\title{
A coastal mean sea surface with associated errors in Norway based on new-generation altimetry
}

Ophaug, Vegard; Breili, Kristian; Andersen, Ole Baltazar

Published in:

Advances in Space Research

Link to article, DOI:

10.1016/j.asr.2019.08.010

Publication date:

2021

Document Version

Peer reviewed version

Link back to DTU Orbit

Citation (APA):

Ophaug, V., Breili, K., \& Andersen, O. B. (2021). A coastal mean sea surface with associated errors in Norway based on new-generation altimetry. Advances in Space Research, 68(2), 1103-1115.

https://doi.org/10.1016/j.asr.2019.08.010

\section{General rights}

Copyright and moral rights for the publications made accessible in the public portal are retained by the authors and/or other copyright owners and it is a condition of accessing publications that users recognise and abide by the legal requirements associated with these rights.

- Users may download and print one copy of any publication from the public portal for the purpose of private study or research.

- You may not further distribute the material or use it for any profit-making activity or commercial gain

- You may freely distribute the URL identifying the publication in the public portal

If you believe that this document breaches copyright please contact us providing details, and we will remove access to the work immediately and investigate your claim. 


\section{Journal Pre-proofs}

A coastal mean sea surface with associated errors in Norway based on newgeneration altimetry

Vegard Ophaug, Kristian Breili, Ole Baltazar Andersen

PII:

S0273-1177(19)30576-9

DOI: https://doi.org/10.1016/j.asr.2019.08.010

Reference:

JASR 14390

To appear in: $\quad$ Advances in Space Research

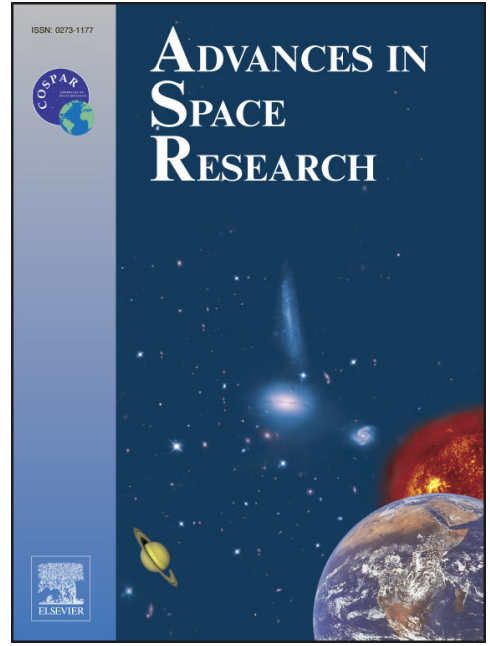

Received Date: $\quad 27$ February 2019

Revised Date: 6 August 2019

Accepted Date: $\quad 8$ August 2019

Please cite this article as: Ophaug, V., Breili, K., Andersen, O.B., A coastal mean sea surface with associated errors in Norway based on new-generation altimetry, Advances in Space Research (2019), doi: https://doi.org/10.1016/ j.asr.2019.08.010

This is a PDF file of an article that has undergone enhancements after acceptance, such as the addition of a cover page and metadata, and formatting for readability, but it is not yet the definitive version of record. This version will undergo additional copyediting, typesetting and review before it is published in its final form, but we are providing this version to give early visibility of the article. Please note that, during the production process, errors may be discovered which could affect the content, and all legal disclaimers that apply to the journal pertain.

(C) 2019 COSPAR. Published by Elsevier Ltd. All rights reserved. 


\title{
A coastal mean sea surface with associated errors in Norway based on new-generation altimetry
}

\author{
Vegard Ophaug ${ }^{1, *}$, Kristian Breili ${ }^{2,1}$, Ole Baltazar Andersen ${ }^{3}$
}

\section{Abstract}

The coastal mean sea surface (MSS) has applications within oceanography as well as geodesy. Together with a geoid model, it forms an important component for geodetic mapping of ocean surface currents that are in geostrophic balance. Furthermore, it forms a bridge between open ocean MSS and in situ measurements of mean sea level at or close to land, it contributes to the mapping of the geoid and the marine gravity field, and it is essential for connecting tidal nautical chart datums to physical height systems or global geodetic reference frames.

In this study, we determine a coastal MSS with an associated error field for Norway. The MSS is solely based on new-generation altimetry data, i.e., SAR(In) data from Sentinel-3A and CryoSat-2, as well as Ka-band data from SARAL/AltiKa. The data sets partly overlap in time and cover the time period from 2010 to 2017 inclusive. We have chosen these altimeters because they represent evolutions of conventional altimetry, with reduced footprint sizes as a main benefit. This is especially advantageous in the coastal zone, as a smaller footprint reduces the probability of radar pulses being contaminated by energy backscattered from land areas.

The satellite missions were harmonized by applying inter-mission biases

*Corresponding author

Email addresses: vegard.ophaug@nmbu.no (Vegard Ophaug),

Kristian.Breili@kartverket.no (Kristian Breili), oa@space.dtu.dk (Ole Baltazar

Andersen)

${ }^{1}$ Faculty of Science and Technology (RealTek), Norwegian University of Life Sciences (NMBU), Po. box 5003, N-1432 Ås, Norway

${ }^{2}$ Geodetic Institute, Norwegian Mapping Authority, Kartverksveien 21, N-3511 Hønefoss, Norway

${ }^{3}$ DTU Space, Technical University of Denmark, Elektrovej, building 327, DK-2800 Kgs. Lyngby, Denmark 
determined in a regional crossover analysis. Furthermore, in a zone closer to land than $25 \mathrm{~km}$, we have replaced the global ocean tide model with a regional ocean tide model provided by the Norwegian Mapping Authority (NMA). We use an optimal interpolation technique to determine a coastal MSS grid and discuss it in context of the estimated error field.

We assess our coastal MSS by comparison to state-of-the-art MSS products along three sections perpendicular to the coast, as well as ellipsoidal mean sea level as observed by an array of permanent tide gauges within the study area. In addition, we assess a higher-resolution version of our MSS in the NMA testbed for vertical datums, by comparison with temporary tide gauges. We find that the coastal MSS outperforms the global MSS models directly at the coast, with standard deviations of differences of $\sim 8 \mathrm{~cm}$ to the tide gauges, compared to $14-22 \mathrm{~cm}$, obtained with the global MSS models. All MSS models largely agree along three sections perpendicular to the coast, with standard deviations of differences of $24 \mathrm{~cm}$. The higher-resolution version of the coastal MSS performs similarly to the coastal MSS in comparison with the temporary tide gauges (standard deviation of differences of $\sim 8 \mathrm{~cm}$ ), but its formal error field also quantifies large uncertainties at the coast and in the fjords, mainly due to the lack of altimetry observations. A trustworthy error field is decisive for the combination of altimetry with other sea-level observations.

Keywords: Sentinel-3; CryoSat-2; SARAL/AltiKa; coastal altimetry; tide gauges; mean sea surface

\section{Introduction}

The ellipsoidal time-mean sea surface (MSS), exempt from tidal and other short-periodic effects, has been observed globally to centimeter accuracy by satellite altimeters since the early 1990s (Stammer and Cazenave, 2017). With ellipsoidally referenced tide-gauge (TG) observations, an equivalent quantity known as mean sea level (MSL) is obtained. By subtraction of the equipotential surface known to geodesists as the geoid from MSS or MSL, the time-mean dynamic topography (MDT) is obtained. This method for determining the MDT is known as the geodetic approach, which contrasts independent oceanographic approaches (e.g., Ophaug et al., 2015; Andersen et al., 2018). Consequently, the MSS and MDT surfaces are of interest to geodesists for connecting different vertical datums, and to oceanographers, 
as the slope of the ocean surface reveals geostrophic surface currents.

In addition to geometric vertical datums, referring to a conventional reference ellipsoid, also physically defined heights exist (e.g., Torge and Müller, 2012). Physical vertical datums are typically national, and have traditionally been referenced to an official MSL value based on one or more TGs, transferred to other locations by means of spirit leveling, giving networks of "heights above sea level". One of the challenges with this apporach is that different height systems will be related to different equipotential surfaces due to the spatial variation of the MDT, leading to height offsets between the systems. Height system unification is therefore an ongoing research area in geodesy (e.g., Woodworth et al., 2012).

Adding to the complexity, a country typically operates with different physical vertical datums on land and at sea, to define heights and depths, respectively. The exact relationship between them is often unknown, see, e.g., Pineau-Guillou and Dorst (2013), Slobbe et al. (2013), Albers (2016), and the references therein. This renders collecting and interpreting data for science and engineering applications in the coastal transition zone challenging. With increased knowledge of the coastal mean sea level and the geoid, both referring to the ellipsoid, a relationship between physical vertical datums on land and at sea can be determined. The Norwegian Mapping Authority (NMA) has established a testbed of about $250 \mathrm{~km} \times 250 \mathrm{~km}$ in size in the coastal area of Sunnmøre for studying the possibility of a common physical vertical datum on land and at sea, see Fig. 1. In order to determine a precise MSL and geoid, a large amount of sea level and gravity data have been collected during the last years in this area.

Satellite altimetry is notorious for facing numerous challenges when approaching the coast, due to land or flat-sea contamination of the radar footprint, as well as degradation of measurement corrections and models (Vignudelli et al, 2011). The Norwegian coast is characterized by thousands of small islands, narrow fjords, rough topography, and complex tidal patterns, adding to the complexity of determining the coastal sea surface. In the later years, there have been launched several new satellite altimeter concepts that all advance coastal altimetry: SARAL/AltiKa, CryoSat-2 and Sentinel-3, see, e.g., Villadsen et al. (2016); Verron et al. (2015); ESA Sentinel-3 Team (2013) for mission details. We label these altimetry missions using the collective term new-generation altimetry, because they represent evolutions of the conventional altimetry concept.

The typical measurement frequency of altimetry satellites is the $\mathrm{Ku}$ band 
(Stammer and Cazenave, 2017). In February, 2013, SARAL/AltiKa was launched, the first altimeter operating on the higher-frequency Ka band. The increased frequency and shorter wavelength of SARAL/AltiKa increases both the vertical (range) and spatial resolution, and gives SARAL/AltiKa a doubled range precision compared with conventional altimetry satellites (Bonnefond et al., 2018). Another altimetry concept is that of the SAR or delay/Doppler altimeter (DDA), suggested by Raney (1998). The main goal of this concept is to improve the determination of geophysical parameters by increasing the number of observations. CryoSat-2 (April 2010) (Wingham et al., 2006) and Sentinel-3A/B (February 2016/April 2018) were launched with the SIRAL and SRAL altimeters, respectively, and are the first altimeter satellites based on DDA. DDA processing reduces the instrument noise as well as the waveform footprint size (i.e., the surface of the sea that is illuminated to create the altimeter waveform), giving a synthetic strip of $\sim 300$ $m$ in the along-track direction, and as large as the typical disc-shaped LRM waveform in the across-track direction, resulting in a footprint area of $\sim 5$ $\mathrm{km}^{2}$ (Dibarboure et al., 2014). Compared to the conventional Jason mission, SARAL/AltiKa decreases the waveform footprint area by a factor of $\sim 3$, DDA processing by a factor of $\sim 60$. SAR altimetry has been shown to improve the mesoscales of the MSS, i.e., for wavelengths between $10 \mathrm{~km}$ and 100 km (e.g., Dibarboure et al., 2014; Raynal et al., 2018).

Purely oceanographic or geodetic MDTs, as well as altimetric versus tidegauge MDTs, can act as each other's buddy check, and increase confidence in the observations and models in use, see, e.g., Ophaug et al. (2015); Idžanović et al. (2017); Huang (2017); Andersen et al. (2018), and the references therein. The different approaches contain different error sources, which can be quantified by setting up error budgets. The applicability of such error budgets, however, depenas on realistic formal error descriptions of the contributing elements.

The main goal of this study is twofold. First, we evaluate the performance of new-generation altimetry data along the Norwegian coast, by determining a coastal MSS with associated error field based on observations from SARAL/AltiKa, CryoSat-2 and Sentinel-3A. We designate this MSS model NMBU18, and compare it with state-of-the-art global MSS models and ellipsoidal MSL in an array of permanent TGs along the Norwegian coast. In addition, we compare the MSS fields along three sections perpendicular to the Norwegian coast, representing areas with comparatively smooth (Northern coast), medium (Southern coast), and rough (Svinøy hydrographic section) 
MDT signal.

Second, we assess whether a higher-resolution version of NMBU18 can be used for vertical reference frame studies in the Sunnmøre testbed, by comparing it with two permanent TGs in the area, as well as 21 temporary TGs that have been operative over different periods during the later years. The empirical and formal errors will help us quantify to which extent altimetry is applicable for establishing a relationship between vertical datums on land and at sea, as a correct error field is necessary when combining altimetry with other sea-level observations.

The data and methods are presented in Section 2, and the results and validation of the coastal MSS are shown in Section 3. We discuss the results and summarize the study in Section 4.

\section{Data and methods}

\subsection{Altimetry data}

For the determination of the coastal MSS, we have used SAR observations from Sentinel-3A, SARIn observations from CryoSat-2, as well as Ka-band observations from SARAL/AltiKa, see Table 1 for details. The data sets partly overlap in time and cover the time period from 2010 to 2017 inclusive.

From its launch in February 2013, the orbit of SARAL/AltiKa was identical to the repetitive orbit of Envisat, with 501 passes and an exact 35day repeat cycle. Due to technical issues in March 2015, it was decided that SARAL/AltiKa would be continued in a non-repeating drifting orbit phase, or geodetic mission (GM), from July 2016. Thus, we have used 1$\mathrm{Hz}$ SARAL/Attika data obtained in both repeat and GM mission phases. The data were obtained from the CNES service Archivage, Validation et Interprétation de données des Satellites Océanographiques (AVISO).

SAR (Sentinel-3A) and SARIn (CryoSat-2) mode observations were obtained from the ESA Grid Processing-On-Demand (GPOD) service (Benveniste et al., 2016), using 1-Hz Level 2 data, which contains range and geophysical corrections, and a height estimate. The data sets from GPOD are based on L2 and $1 \mathrm{~Hz}$ L1b data retracked with the SAR Altimetry Mode Studies and Applications (SAMOSA) 2 (Cryosat-2) and SAMOSA+ (Sentinel-3A) physical retrackers. Where applicable, the SARIn off-nadir range correction was applied in the processing. The GPOD processing is done on the $20-\mathrm{Hz}$ data, and subsequently averaged to $1 \mathrm{~Hz}$, increasing the chance of obtaining reliable observations even in the fjords and skerries. We use $1-\mathrm{Hz}$ data as 

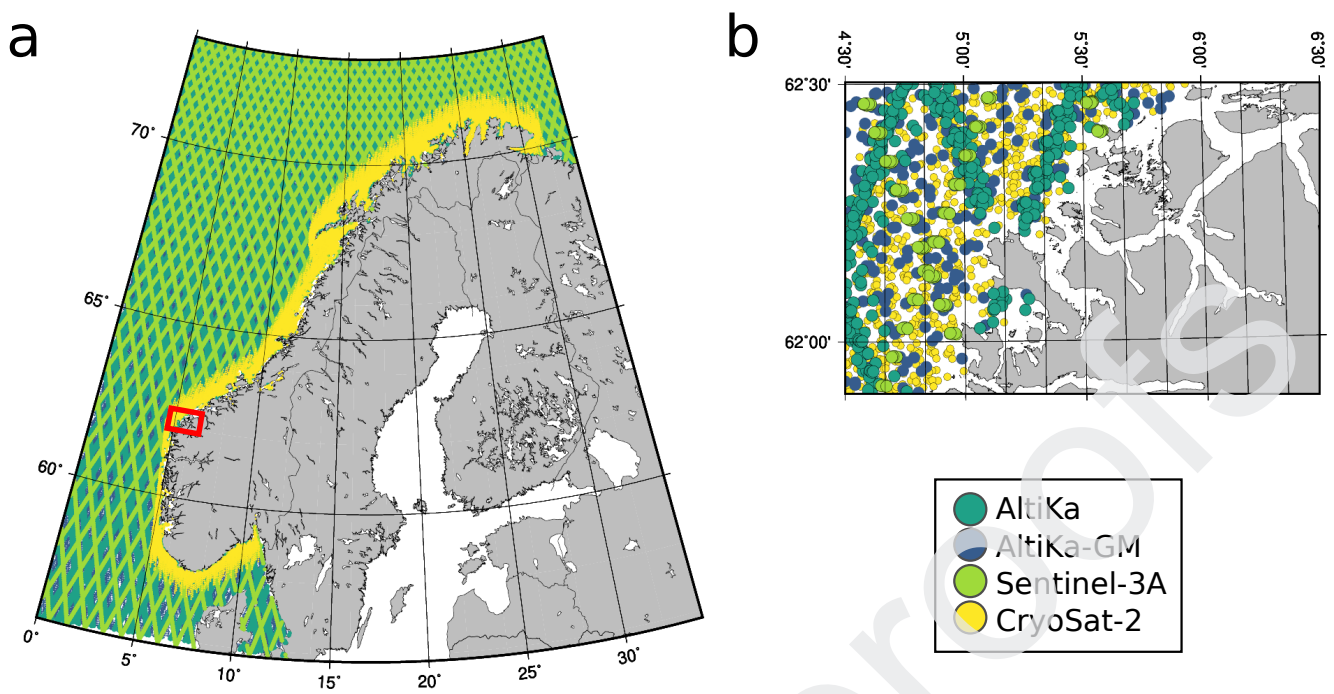

Figure 1: New-generation altimetry data used for (a) NMBU18, covering the Norwegian coast, and (b) NMBU18S, covering the Sunnmøre testbed (its location is marked by the red box in panel (a)).

they are less noisy than the $20-\mathrm{Hz}$ data, and to obtain a consistent combined data set.

The altimetry observations listed in Table 1 were preprocessed in several steps. First, the observations were edited using a subset of the criteria listed in the SARAL/AltiKa handbook (Bronner et al., 2013). In addition, a high-resolution coastline from OpenStreetMap (OpenStreetMap contributors, 2018) was used as a land/sea mask. Remaining observations from the first step were subjected to a multiple Student's $t$-test (Koch, 1999). The test was applied individually to each pass in order to identify and eliminate significant outliers. The resulting edited data set comprises 617,698 observations ( 50\% SARAL/AltiKa, 23\% SARAL/AltiKa-GM, 21\% Sentinel-3A, and $\sim 6 \%$ CryoSat-2), see Fig. 1.

Standard corrections were applied to the altimeter data (note that the sea state bias correction was not applied as it was unavailable), with the exception of the global ocean tide (GOT) model, where instead a regional OT (ROT) model provided by the NMA was tested. The ROT is based on observations from the Norwegian network of permanent and temporary TGs. It is computed for a number of tidal zones along the Norwegian coast, with the outer seaward zone boundaries varying between $30 \mathrm{~km}$ to $90 \mathrm{~km}$ off the 


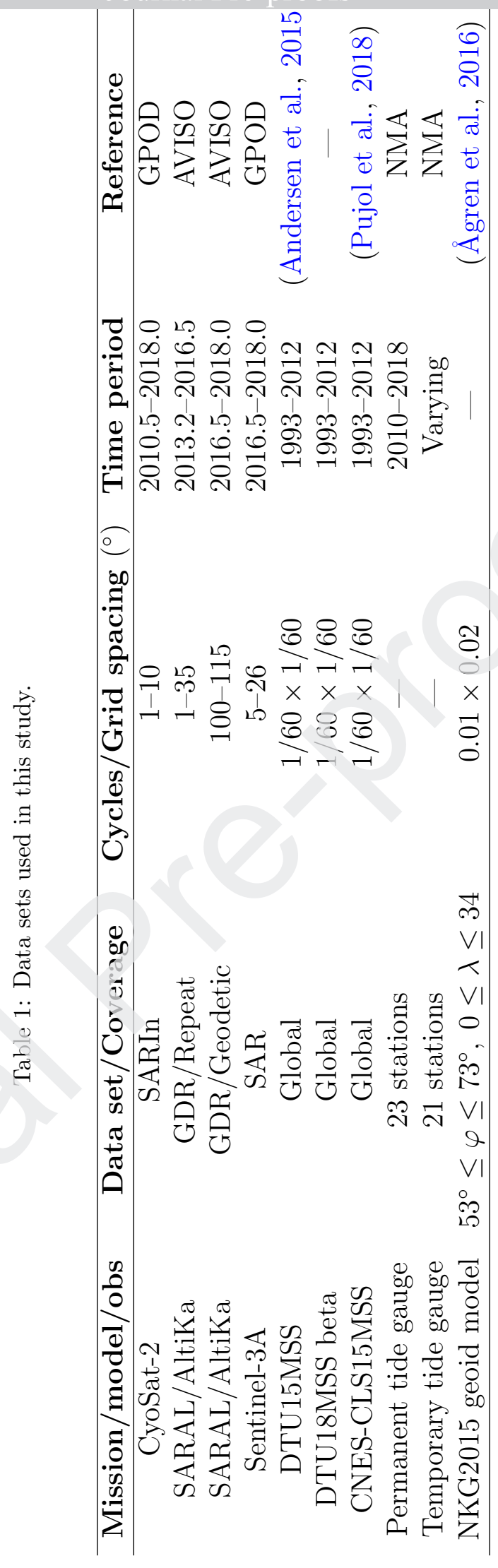


coast. Figure 2 shows variance differences of sea level anomalies (SLAs) for all altimetry missions, processed with the GOT and ROT. For SARAL/AltiKa and Sentinel-3A, the variance differences are larger than zero within $\sim 45$ $\mathrm{km}$ from the coastline, indicating a reduction of variance with ROT. Within $\sim 15 \mathrm{~km}$, the variance differences are positive also for CryoSat-2. In general, the variance differences are largest when approaching the coast, especially for Sentinel-3A and CryoSat-2. This indicates that the largest differences between GOT and ROT are found closest to the coastline, where the latter is assumed to be the most accurate. The negative variance differences for CryoSat-2 between $25 \mathrm{~km}$ and $50 \mathrm{~km}$ from the coastline, however, indicate that GOT is better than ROT in this area, which remains a topic for further investigations.

As ROT generally reduces the SLA variances the most along the coast, we replaced GOT with ROT where ROT is available, implying that a mix of models was used. A known inconsistency between GOT and ROT is that the latter does not include the ocean tide loading (OTL) effect, as it is based on TG observations. Using both the FES2004 and GOT4.8 OTL solutions of the SARAL/AltiKa dataset, we found that OTL varies between $\pm 3 \mathrm{~cm}$ along the Norwegian coast, and the variation does not appear to increase significantly on the open ocean ( $>50 \mathrm{~km}$ off the coast). While we could expect a slight improvement of ROT when including the effect of OTL, the variance differences of SARAL/AltiKa and Sentinel-3A show a clear improvement with ROT even though it does not include the OTL effect, which justifies its use. We determined the mean difference between all observations where both GOT and ROT is available to $-0.59 \mathrm{~cm} \pm 0.03 \mathrm{~cm}$, and the mean difference between observations $>20 \mathrm{~km}$ off the coast to $-0.63 \mathrm{~cm} \pm 0.04 \mathrm{~cm}$. The latter estimate includes points where we assume that GOT outperforms ROT due to the long distance to the TGs of the latter. These results indicate that there is a small sub-cm bias between GOT and ROT, which we consequently did not correct for.

The datasets were harmonized by applying inter-mission biases estimated in an SSH crossover adjustment. We closely followed the approach of Bosch et al. (2014), but used the data from the study area only. We chose SARAL/AltiKa as reference mission due to its long time series and data covering the entire study area. The biases of Sentinel-3A and CryoSat-2 with respect to SARAL/AltiKa were estimated to $43.8 \mathrm{~mm}$ and $61.6 \mathrm{~mm}$, respectively.

Furthermore, seasonal signals were removed from the filtered, edited, harmonized, and merged data. This was done by individually estimating the 


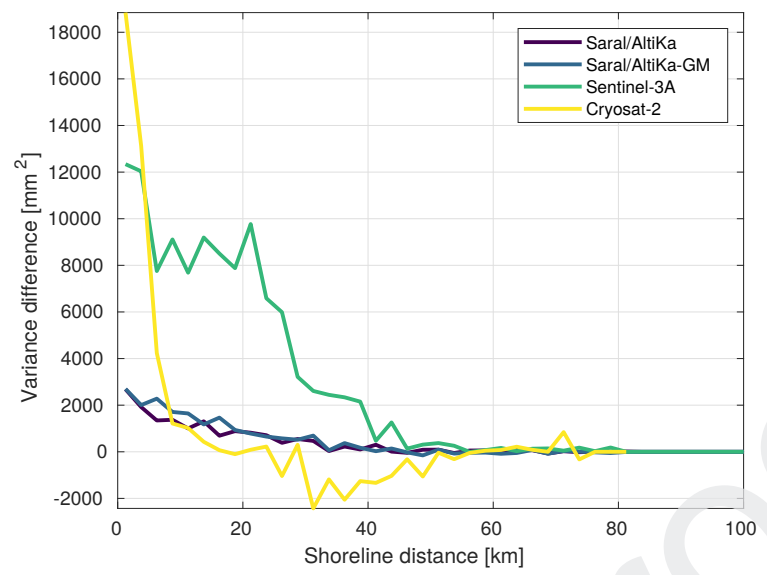

Figure 2: Variance differences between SLAs corrected with GOT and ROT for different altimetry missions as a function of distance from the coast.

annual and semi-annual harmonics by least-squares adjustment from altimetry observations in $1^{\circ} \times 1^{\circ}$ bins. Removing inter-mission biases and seasonal signals reduced in total the standard deviation of the data set by $16 \%$. The altimetry observations refer to the WGS84 ellipsoid and are given in the mean permanent tide system (MT), as do the resulting NMBU18 and NMBU18S mean sea surfaces.

\subsection{The $N M B U 18$ and $N M B U 18 S$ coastal mean sea surfaces}

Our observation data only covers the Norwegian coastal region, which makes us unable to suificiently approximate the long wavelengths of the MSS signal. We therefore perform field approximation in terms of MDT, where the geoid has been subtracted a priori, and is subsequently restored, i.e., a "remove-restore" approach (e.g., Andersen, 2013).

Geodetic MDT values were formed by referencing the SSHs to the NKG2015 geoid model (Ågren et al., 2016). This geoid model is based on the fifth release data from the European Space Agency satellite gravity mission Gravity and steady-state Ocean Circulation Explorer (GOCE) (Drinkwater et al., 2003). The geoid heights refer to the WGS84 ellipsoid. Regarding permanent tides, the geoid heights were transformed from the zero tide (ZT) system to the MT system using Ekman (1989).

In geodesy, a typical method for optimal interpolation (OI) or field approximation is least-squares prediction (LSP). LSP is a special case of the 
more general least-squares collocation method (e.g., Moritz, 1980), and aims to minimize the misfit of the analysis in a least-squares sense, using weights that are determined from a study of signal covariances between data points as a function of the distance between them. The well-known main drawbacks of OI are its dependence on a correctly modeled covariance function, as well as its numerical cost. The analysis is done in the data space, with a $n \times n$ matrix to be inverted, where $n$ is the number of data points.

Instead, we have performed the field approximation of the MDT values using the Data-Interpolating Variational Analysis (DIVA) gridding tool (Troupin et al., 2012), as it is designed to deal with a large number of observations and is influenced directly by the geometry of the area of interest (preventing the flow of information across boundaries), here the intricate Norwegian coastline. The gridded field is obtained through the variational inverse method (VIM), as the solution of a cost function that penalizes the misfit between the data and the gridded field, as well as the regularity of the latter (a smoothness constraint). The minimization of the cost function is done using the finite-element method (FEM), where the solution is computed on a set of triangles covering the area of interest. The main advantages of using the FEM is that boundaries are taken into account (i.e., non-isotropy), and that the numerical cost is close to independent of the number of data points. A drawback of DIVA is that covariances are never explicitly formulated. While the covariance function of $\mathrm{OI}$ is known analytically and facilitates easy estimation of formal analysis errors, it must be numerically estimated in DIVA, at a larger computational cost. It can be shown, however, that, although formally different, OI and VIM can give identical results, provided that certain criteria are fulfilled. Two main analysis parameters control the DIVA analysis, i.e., the correlation length $L$ (the distance over which a data point influences its neighbors) and the signal-to-noise ratio (SNR $=C_{0} / \epsilon^{2}$, where $C_{0}$ is the signal variance and $\epsilon^{2}$ is the error variance). Both parameters are empirically determined by the divafit fitting routine of DIVA.

We determine NMBU18 on a regular grid extending from $0^{\circ} \mathrm{E}$ to $34^{\circ} \mathrm{E}$, and from $55.83^{\circ} \mathrm{N}$ to $73^{\circ} \mathrm{N}$, with a $1-\mathrm{km}$ resolution. As this resolution is a little coarse for detailed investigations in the Sunnmøre testbed, we perform a second analysis using altimetry data in the testbed only. We designate this model NMBU18S, with its regular grid extending from $4.5^{\circ} \mathrm{E}$ to $6.5^{\circ}$ $\mathrm{E}$, and from $61.9^{\circ} \mathrm{N}$ to $62.5^{\circ} \mathrm{N}$, with a $100-\mathrm{m}$ resolution. The land-sea contours were determined using the OpenStreetMap coastline. $L$ was empirically determined to $\sim 280 \mathrm{~km}$ and $\sim 11 \mathrm{~km}$ for NMBU18 and NMBU18S, 
a

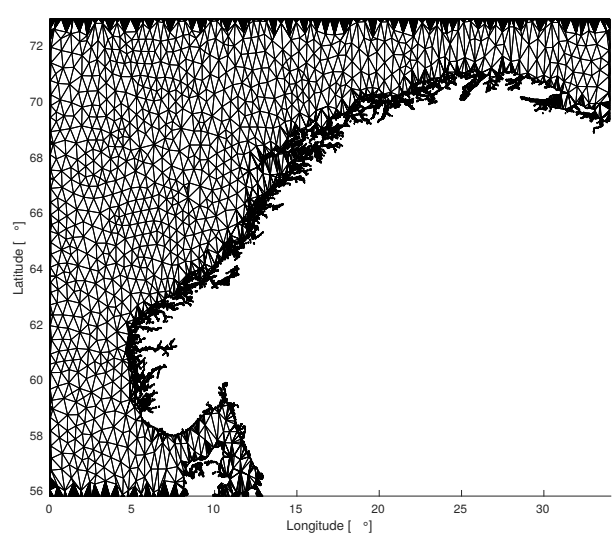

b

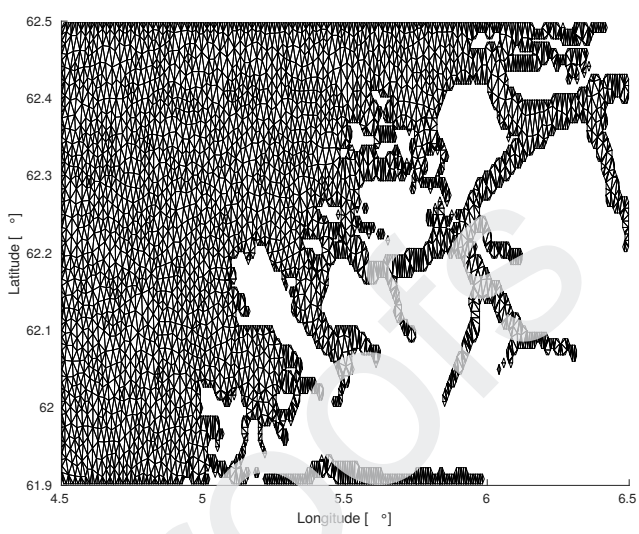

Figure 3: Finite-element mesh for (a) NMBU18 (the Norwegian coast) and (b) NMBU18S (the Sunnmøre testbed).

respectively, and the resulting finite-element meshes based on the contours and the analysis parameters are shown in Fig. 3.

There are several methods for estimating formal error fields available in DIVA, characterized by their degree of approximation and computation cost. For a detailed description of each method, see Troupin et al. (2012) and Beckers et al. (2014). We apply the "Real Covariance" method, which is the numerically most expensive method, but gives the most accurate error field, related to the actual covariance. As mentioned, it is not straightforward to compute the error feld in DIVA because the covariance function is never explicitly determined. This is remedied through an elaborate scheme where the real covariance function is obtained by two concurrent executions of DIVA, the first providing the covariances for the second. With the covariances at hand, DIVA exploits the equivalence between OI and VIM, and the error is computed using the formulation of the former. This method takes the coastiine effect fully into account, which is of particular interest to our case.

From a least squares fit of NMBU18 interpolated to the TGs and weighted by its error field, we estimated an absolute bias between NMBU18 and the permanent TGs of $-3.7 \mathrm{~mm} \pm 14.1 \mathrm{~mm}$. As this bias is insignificant, we did not apply it to NMBU18. By contrast, an absolute bias of $-213.8 \mathrm{~mm} \pm$ $16.5 \mathrm{~mm}$ was estimated between NMBU18S and the temporary TGs, which is significant, and was applied. 


\subsection{Global mean sea surface models}

We have used three multimission global mean sea surface (MSS) models for our comparison; the French Space Agency (CNES) CNES-CLS15 MSS (Pujol et al., 2018), the Technical University of Denmark DTU15 MSS (Andersen et al., 2015) as well as a beta version of DTU18 MSS with improvements especially affecting the northern coast of Norway, see Table 1 . The main differences between the global MSS models are due to different altimeter measurements used in their estimation, as well as processing approaches (Pujol et al., 2018).

All MSS fields are averaged over the 1993-2012 period, and were referenced to the 2010-2018 period using a TG-based regional sea-level rate of $3.2 \mathrm{~mm} \mathrm{yr}^{-1}$ (Breili et al., 2017). They are given in the MT system and refer to the TOPEX ellipsoid. They were referenced to the WGS84 ellipsoid prior to the validation. As the global MSS models are not meant for coastal applications, we did not estimate a bias between them and the TGs. The global MDT models were computed using NKG2015.

\subsection{Tide-gauge data}

To assess NMBU18 and NMBU18S, we have used MSL calculated at 23 permanent TGs along the Norwegian coast. In addition, we have considered 21 temporary TGs in the Sunnmøre testbed, see Table 1, Figs. 4, 7, and Table 2.

At all tide gauges, water level observations referenced to the tide gauge zero (TGZ) were provided by the NMA. The TGZs have known heights in the national height system of Norway, NN2000, and can be converted to ellipsoidal heights at epoch 2000.0 and referred to the WGS84 ellipsoid by using the height reference surface HREF (Solheim, 2000). The ellipsoidal height at the observation epoch can then be found by taking into account the effect of vertical land motion, which along the Norwegian coast is dominated by Glacial Isostatic Adjustment. We used vertical land motion rates based on observations from GNSS and leveling (Simpson et al., 2017), ranging from 1.3 to $5.1 \mathrm{~mm} / \mathrm{yr}$. Finally, the TG observations were applied corrections for the inverse barometer (IB) effect as well as the ocean tide (no seasonal term included), and averaged over the period 2010 to 2018. The IB correction was computed using the standard equation (Andersen and Scharroo, 2011), and local pressure observations at each TG, with the exception of Hammerfest, where pressure observations from a nearby $(\sim 2 \mathrm{~km})$ meteorological station were used instead. Because HREF is derived from ellipsoidal heights in the 
permanent tide free (TF) system, any height derived using HREF will also be in the TF system. The ellipsoidal heights of MSL were converted to the MT system using Petit and Luzum (2010). Geodetic MDT values were computed using NKG2015.

\section{Results}

We have assessed the MSS models in terms of MDT, where all refer to the NKG2015 geoid. This is done because both the spatial variation and error of the marine geoid would otherwise hamper our assessment, and the quality of the marine geoid is not the topic of this study.

Figures 4a and 4b show NMBU18 MDT and its associated error field, respectively. Qualitatively, it compares well with the known MDT pattern in the Norwegian Sea (e.g., Idžanović et al., 2017), with larger MDT values towards the coast and the Baltic Sea, and smaller values towards the open ocean. Both the Norwegian Atlantic Current and the Norwegian Coastal Current are evident in it. The formal errors range from $6-8 \mathrm{~cm}$ on the open ocean, and quickly increase to $>10 \mathrm{~cm}$ very close to the coast and in the margins of the model. They mainly reflect the availability of data (compare with Fig. 1a).

Figure 5 shows NMBU18 together with CNES-CLS15, DTU15, and DTU18 beta, along the three profiles perpendicular to the coast. Note the different MDT signal characteristics of the profiles (Fig. 5a,c,e). In Figure 5b,d,f, also the closest TG MDT value is shown, indicating that NMBU18 generally fits better to the nearest TG MDT than the global MSS models. All MSS models largely agree along the sections. However, they agree less in areas where the MDT signal variation is small, in the sense that the SNR is smaller here. This is particularly evident along the Northern coast section (Fig. 5b), where the MSS model spread is relatively large close to the coast. This could be owing to NMBU18 resolving smaller scales than the global MSS models, or, alternatively, to NMBU18 being over-smoothed. As a result, a slightly different choice of Northern coast section could give a better fit between all models. A known issue with DTU15 in the Northern coast area was corrected in DTU18 beta, and the latter now nicely aligns with CNES-CLS15. Also evident in Fig. 5 is that NMBU18 is smoother than the global MSS models. The quantitative comparison of the MDT models along the sections is summarized in Table 3. Along the smooth Northern coast profile, NMBU18 shows standard deviations of differences (correlations) of $4.4 \mathrm{~cm}(63.2 \%)$, 


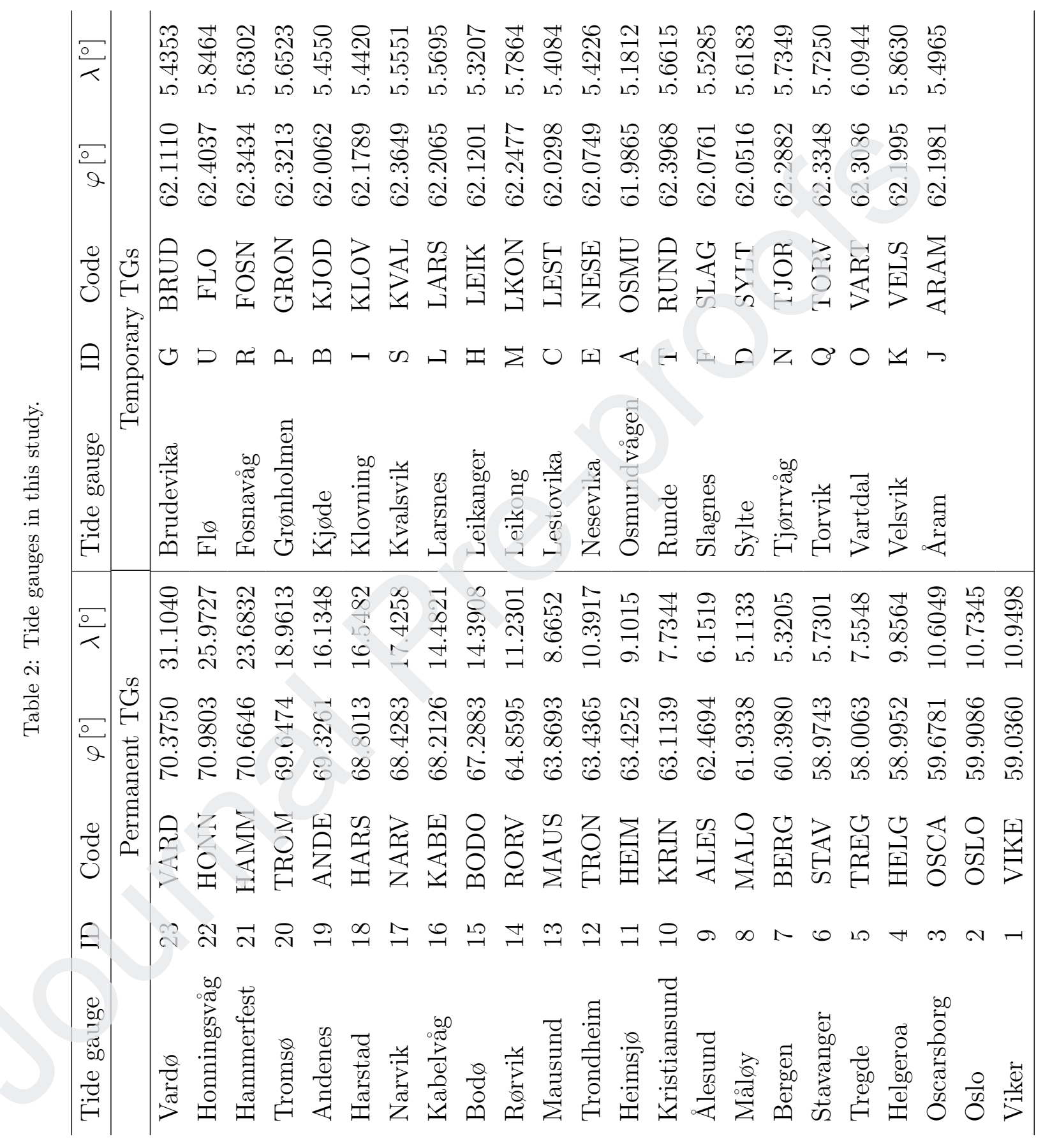


a

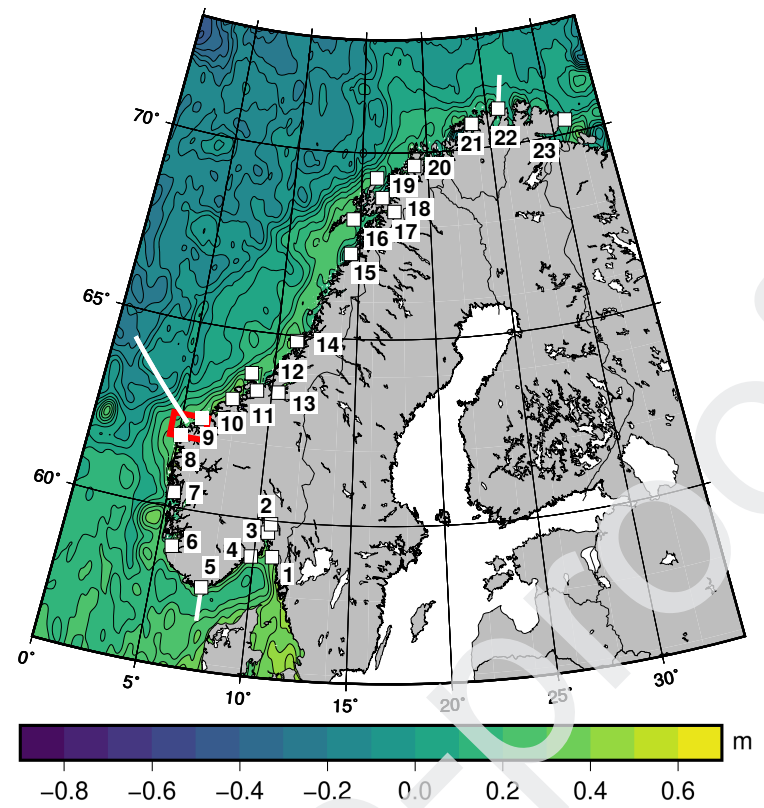

b

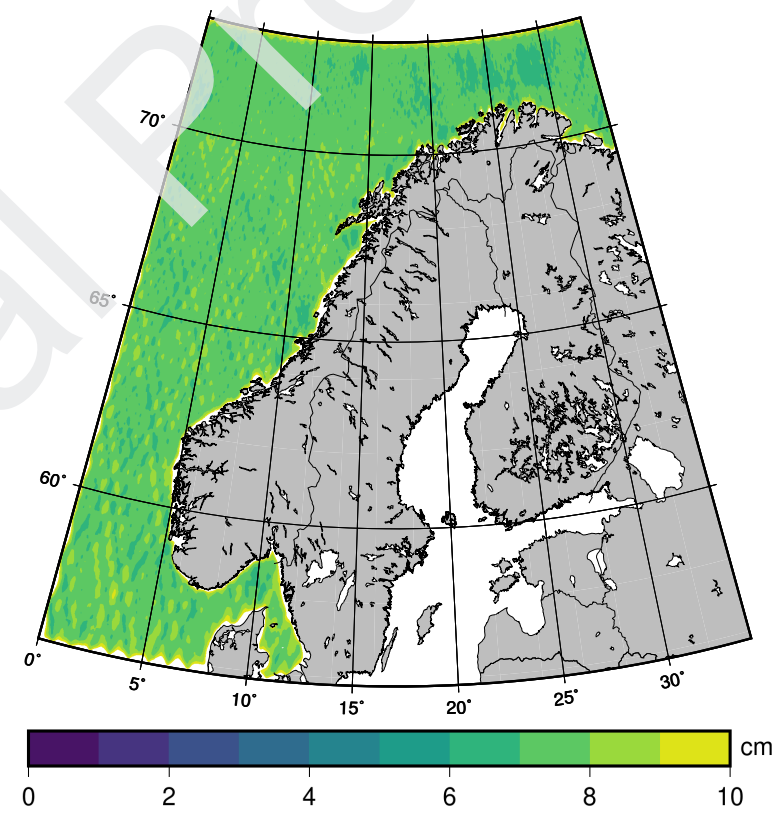

Figure 4: MDT from NMBU18 (a), and its formal errors (b). Panel (a) also shows the locations of the permanent TGs (numbered from 1-23, from south to north), three sections perpendicular to the coast (solid white lines), and the Sunnmøre testbed (red box). The TG identifiers are given in Table 2. 
$3.4 \mathrm{~cm}(88.6 \%)$, and $2.1 \mathrm{~cm}(86.8 \%)$, to DTU15, DTU18 beta, and CNESCLS15, respectively. The numbers improve slightly for the Southern coast profile, where NMBU18 shows values of $2.0 \mathrm{~cm}(93.0 \%), 1.9 \mathrm{~cm}(93.0 \%)$, and $1.7 \mathrm{~cm}(86.8 \%)$, respectively. The smallest numbers are obtained along the rough Svinøy hydrographic section, where NMBU18 shows values of $1.6 \mathrm{~cm}$ (99.2\%), $1.6 \mathrm{~cm} \mathrm{(99.2 \% ),} \mathrm{and} 1.7 \mathrm{~cm} \mathrm{(99.2 \% ),} \mathrm{to} \mathrm{DTU15,} \mathrm{DTU18} \mathrm{beta,} \mathrm{and}$ CNES-CLS15, respectively. We consider these numbers as promising, and they give us confidence in the ability of NMBU18 to describe general MDT features off the coast.

Figure 6a shows the MDT profile along the Norwegian coast, sampled at the permanent TGs. Again, we note that NMBU18 is smoother than CNES-CLS15 and DTU15/18 beta. In general the MDT rises about $20 \mathrm{~cm}$ from north to south, which is in agreement with previous studies (Ophaug et al., 2015; Idžanović et al., 2017). CNES-CLS15 performs worst at the TGs, while a notable improvement is seen in DTU15, D TU18 beta, and NMBU18. The discrepancies seen in Troms $\varnothing$, Narvik, Trondheim, Oscarsborg, and Oslo are likely due to their locations with few valid data points, but CNES-CLS15 struggles also at TGs that are more to the open ocean, such as Bodø, Rørvik, and Kristiansund. The quantitative comparison is summarized in Table 3. In comparison with the permanent TGs, CNES-CLS15, DTU15, DTU18 beta, and NMBU18 show standard deviations of differences (correlations) of 22.5 $\mathrm{cm}(2.5 \%), 14.7 \mathrm{~cm}(12.6 \%), 14.0 \mathrm{~cm}(21.5 \%)$, and $8.2 \mathrm{~cm}(65.5 \%)$, respectively.

We regard the performance of NMBU18 as promising, as previous studies of coastal MDT have shown an agreement between geodetic and oceanographic MDTs on the 2-14-cm level (Ophaug et al., 2015; Idžanović et al., 2017; Huang, 2017). In a recent study by Andersen et al. (2018), MDT determined by both geodetic and oceanographic approaches were compared to MDT determined by TG observations. They found an average misfit of $\sim 9$ $\mathrm{cm}$, and they attribute the bulk of it to small-scale errors in the marine geoid (see also Sect. 4).

This study considers all the permanent TGs along the mainland coast of Norway. In their comparison of an altimetric-geodetic MDT (solely based on CryoSat-2) at 19 permanent TGs in Norway (omitting Narvik, Trondheim, Oscarsborg, and Oslo, due to their locations well inside fjords with few altimeter data), Idžanović et al. (2017) found an agreement of 4-5-cm. Omitting these TGs from the present comparison, CNES-CLS15, DTU15, DTU18 beta, and NMBU18 all show smaller standard deviations of differ- 
a

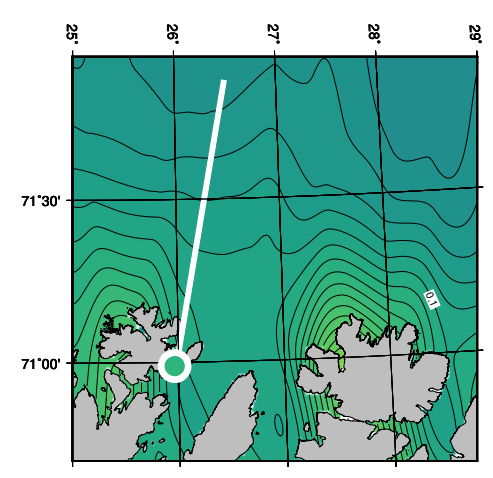

C

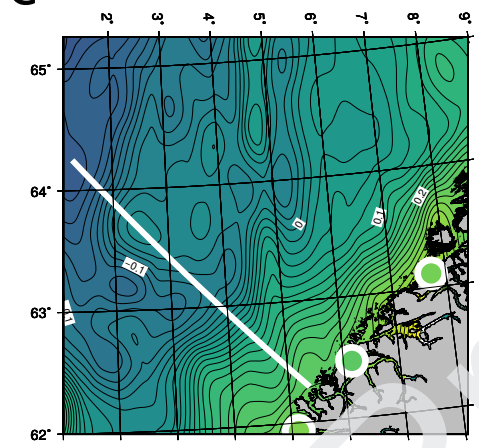

e

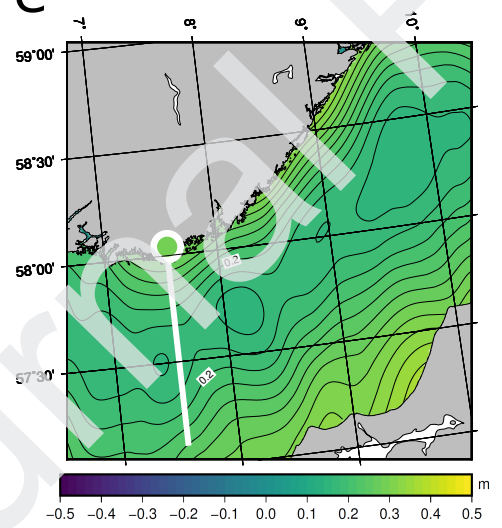

b
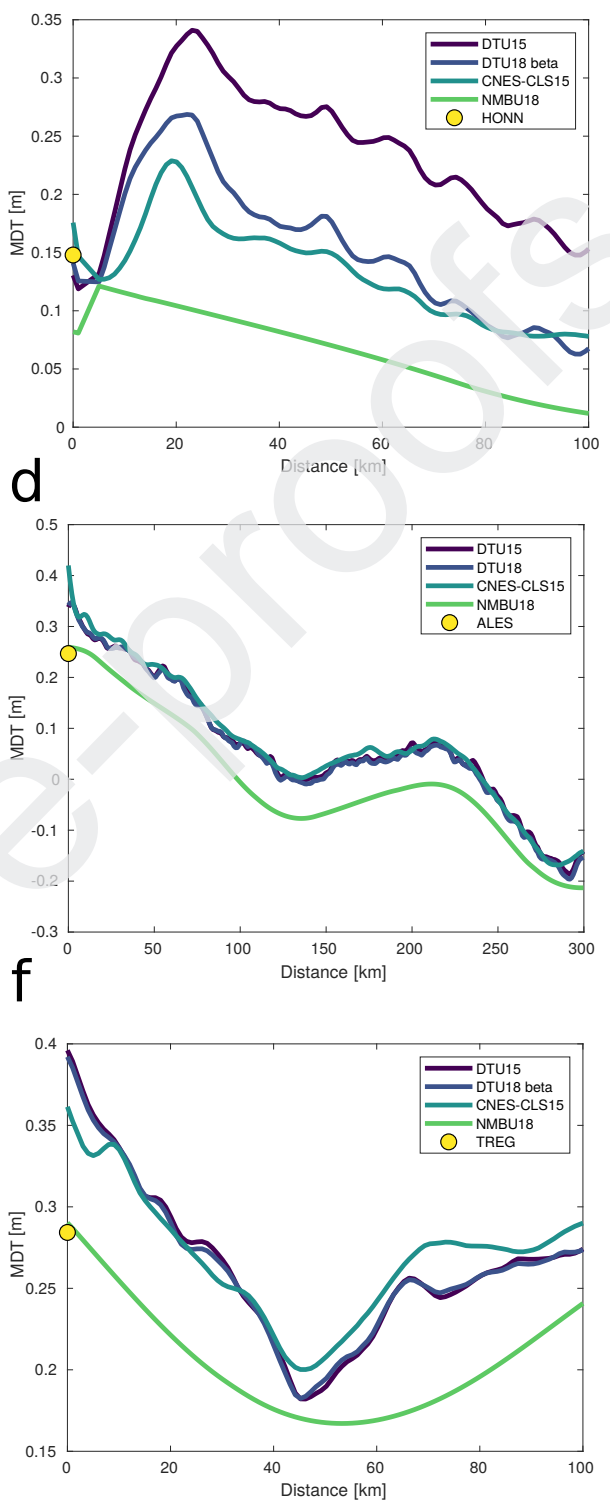

Figure 5: Comparison of MDT along three sections perpendicular to the Norwegian coast; Northern coast (a) and (b), Svinøy hydrographic section (c) and (d), and Southern coast (e) and (f). (a), (c), (e) show the geographic location of the sections, superimposed on the NMBU18 MDT, as well as the MDT values of nearby TGs. (b), (d), (f) show MDT along the respective cross-sections using different MSS models, all referenced to the NKG2015 geoid model. In addition, the MDT value of the nearest permanent TG is shown (HONN, ALES, and TREG, cf. the TG identifiers in Table 2). 
Table 3: Comparison of different MDT models at profiles and TGs (standard deviations $(\hat{\sigma})$ and root-mean-square (RMS) values in $\mathrm{cm}$, correlations $(\rho)$ in \%).

\begin{tabular}{|c|c|c|c|c|c|c|}
\hline Observation/Model & $\min$ & $\max$ & mean & $\hat{\sigma}$ & RMS & $\rho$ \\
\hline & \multicolumn{6}{|c|}{ Southern coast profile } \\
\hline DTU15 & 18.2 & 39.6 & 26.2 & 4.7 & & \\
\hline DTU18 beta & 18.2 & 39.2 & 26.2 & 4.6 & & \\
\hline CNES-CLS15 & 20.0 & 36.1 & 26.8 & 3.8 & & \\
\hline NMBU18 & 16.7 & 29.0 & 20.4 & 3.3 & & \\
\hline NMBU18-DTU15 & -10.6 & -1.2 & -5.8 & 2.0 & 6.2 & 93 \\
\hline NMBU18-DTU18 & -10.2 & -1.2 & -5.8 & 1.9 & 6.1 & 93 \\
\hline \multirow[t]{2}{*}{ NMBU18-CNES-CLS15 } & -9.8 & -3.0 & -6.4 & 1.7 & 7.0 & 86.8 \\
\hline & \multicolumn{6}{|c|}{ Svinøy hydrographic section } \\
\hline DTU15 & -18.6 & 34.7 & 6.4 & 12.6 & & \\
\hline DTU18 beta & -19.6 & 34.6 & 5.9 & 12.9 & & \\
\hline CNES-CLS15 & -16.8 & 42.0 & 7.1 & 13.0 & & \\
\hline NMBU18 & -21.3 & 26.0 & -0.3 & 12.5 & & \\
\hline NMBU18-DTU15 & -10.2 & -2.5 & -6.7 & 1.6 & 6.8 & 99.2 \\
\hline NMBU18-DTU18 & -9.5 & -1.5 & -6.2 & 1.6 & 6.4 & 99.2 \\
\hline \multirow[t]{2}{*}{ NMBU18-CNES-CLS15 } & -16.0 & -3.1 & -7.4 & 1.7 & 7.6 & 99.2 \\
\hline & \multicolumn{6}{|c|}{ Northern coast profile } \\
\hline DTU15 & 11.9 & 34.1 & 23.6 & 5.7 & & \\
\hline DTU18 beta & 6.3 & 26.9 & 15.3 & 6.0 & & \\
\hline CNES-CLS15 & 7.8 & 22.9 & 13.3 & 4.3 & & \\
\hline NMBU18 & 1.2 & 12.1 & 6.6 & 3.3 & & \\
\hline NMBU18-DiU15 & -24.0 & -1.0 & -17.0 & 4.4 & 17.6 & 63.2 \\
\hline NMBU18-DTU18 & -16.7 & -0.4 & -8.7 & 3.4 & 9.4 & 88.6 \\
\hline NMBU18-CNES-CLS15 & -12.4 & -0.6 & -6.7 & 2.1 & 7.0 & 86.8 \\
\hline & \multicolumn{6}{|c|}{ Permanent tide gauges } \\
\hline $\mathrm{TG}$ & 12.2 & 36.4 & 24.7 & 6.7 & & \\
\hline DTU15 & -1.7 & 46.6 & 27.0 & 14.0 & & \\
\hline DIU18 beta & -5.5 & 46.4 & 25.5 & 13.8 & & \\
\hline CNES-CLS15 & -1.6 & 84.7 & 30.2 & 21.7 & & \\
\hline NMBU18 & 7.8 & 46.0 & 25.2 & 10.8 & & \\
\hline DTU15-TG & -24.6 & 24.4 & 2.2 & 14.7 & 14.6 & 12.6 \\
\hline DTU18-TG & -28.5 & 21.3 & 0.8 & 14.0 & 13.7 & 21.5 \\
\hline CNES-CLS15-TG & -33.9 & 58.9 & 5.5 & 22.5 & 22.7 & 2.5 \\
\hline NMBU18-TG & -11.3 & 20.2 & 0.5 & 8.2 & 8.0 & 65.5 \\
\hline
\end{tabular}


ences (correlations) of $15.5 \mathrm{~cm}(18.0 \%), 14.6 \mathrm{~cm}(12.5 \%), 13.9 \mathrm{~cm}(17.7 \%)$, and $6.3 \mathrm{~cm}(79.0 \%)$, respectively, with NMBU18 approaching the results of Idžanović et al. (2017).

Motivated by the performance of NMBU18, we wish to explore whether it is applicable for the challenging task of determining a common vertical reference frame on land and at sea in the Sunnmøre testbed. The combination of reference frames will practically take the form of a conversion (or separation) surface, which error will be a combination of errors in all data sets used to generate it (Mills and Dodd, 2014). Thus, the decisive element for the application of altimetry to this task will be the determination of a realistic error field.

The higher-resolution MSS field for this area, NMBU18S, as well as its associated error field, is shown in Fig. 7a,b. Qualitatively, NMBU18S agrees with NMBU18 (compare Fig. 4a with Fig. 7a). NMBU18S confirms the tendency of MDT to fall towards zero beyond the observed (and expected) rise of MDT towards the coast. We attribute this fall to the fact that there are few altimetry observations in that area (see also Sect. 4). This is reflected well in the notably increased uncertainties observed in the NMBU18S error field (Fig. 7b). The error field (Fig. 7b) is in accordance with NMBU18 (Fig. 4b), with a coastal error of $\sim 10 \mathrm{~cm}$, but increasing to $\sim 30 \mathrm{~cm}$ and beyond when following the fjords inwards. Figure $6 \mathrm{~b}$ shows the MDT profiles of NMBU18S and NMBU18, sampled at two permanent TGs in the Sunnmøre testbed (Måløy and Ålesund), as well as 21 temporary TGs. We first note that NMBU18 is smooth when compared with NMBU18S, reflecting the higher resolution of the latter. Måløy shows a larger discrepancy for NMBU18S than for NMBU18, which could be owing to the fact that it is in the border area of NMBU18S, with fewer observations available for its estimation. The large discrepancies in, e.g., Fosnavåg, Leikong, and Osmundvågen are likely due to their tricky land- and skerry-confined locations. NMBU18S agrees well with temporary TGs in the coastal margin, such as Kvalsvik, Runde, Flø, and Torvik. It also agrees well with some of the TGs in the sparsely observed Vanylven fjord, i.e, Nesevika, Slagnes, and Klovning, but less with the remaining ones (Vartdal, Brudevika, and Leikanger). The quantitative comparison is shown in Table 4. NMBU18S shows a standard deviation of differences (correlation) of $8.1 \mathrm{~cm}(22.7 \%)$ to the TGs in the Sunnmøre testbed. We regard these numbers with cautious optimism considering the relatively short average operation period of the temporary TGs of $\sim 90$ days. However, the discrepancies of the temporary TGs show maximum 

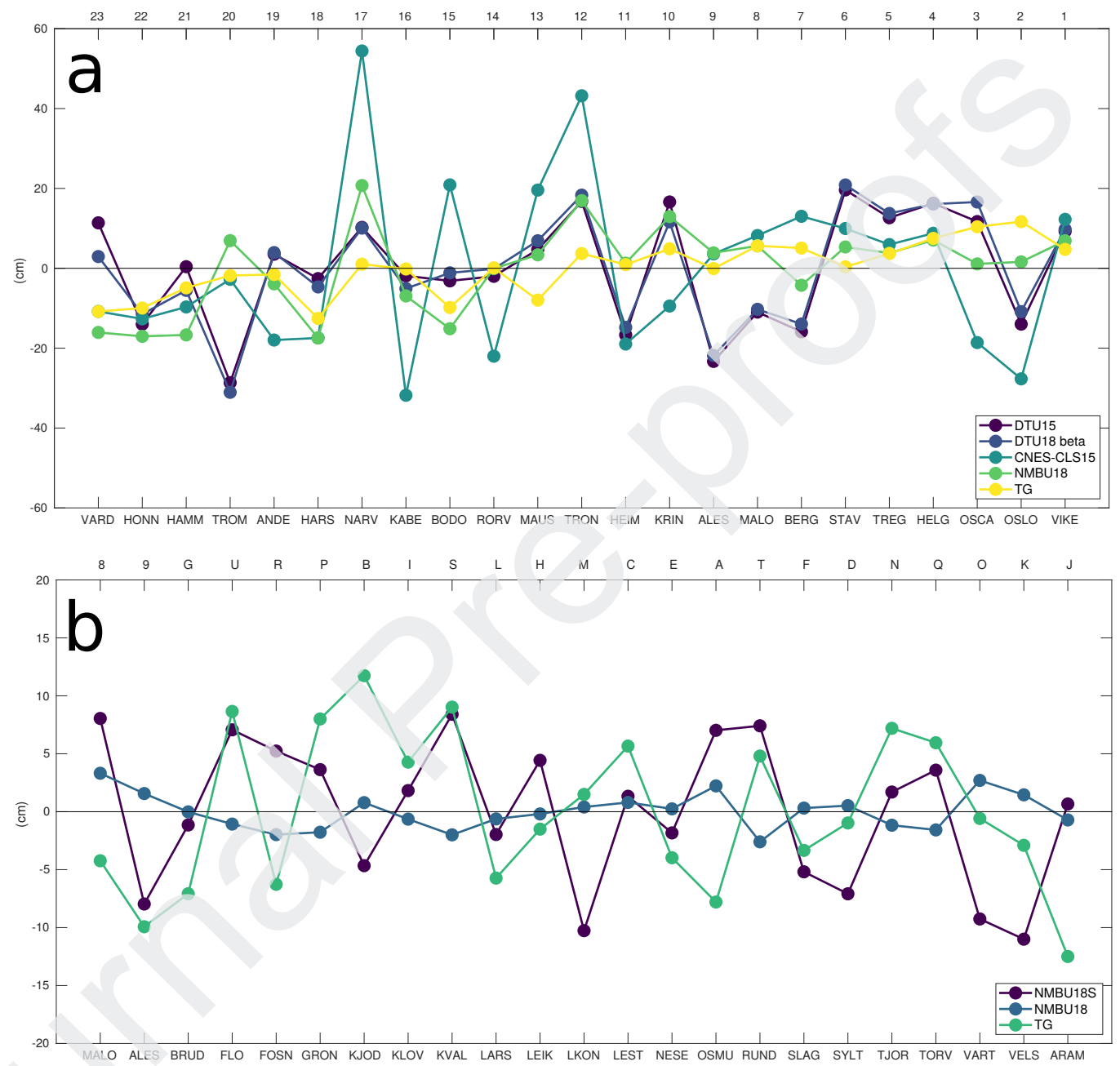

Figure 6: MDT profiles from TG observations and altimetry at a) 23 permanent TGs along the Norwegian coast and at b) two permanent and 21 temporary TGs in the Sunnmøre testbed. The identifiers are defined in Table 2. 

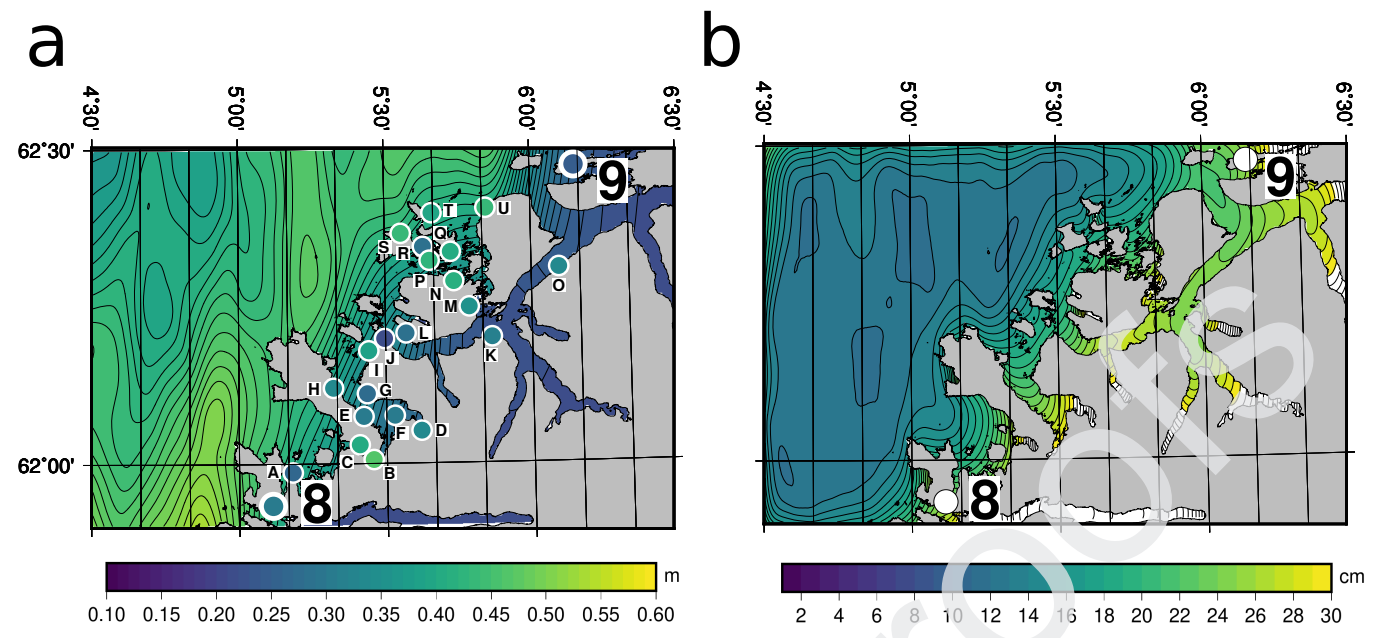

Figure 7: MDT from mean sea surface model NMBU18S referenced to the NKG2015 geoid model (a), as well as its formal errors (b). Also shown are the locations of two permanent and 21 temporary TGs (the latter labeled from A U, from south to north). The TG identifiers are given in Table 2.

Table 4: Comparison of different MDT models at two permanent and 21 temporary TGs in the Sunnmøre testbed (standard deviations $(\hat{\sigma})$ and root-mean-square (RMS) values in $\mathrm{cm}$, correlations $(\rho)$ in \%).

\begin{tabular}{lcccccc}
\hline Observation/Model & min & max & mean & $\hat{\sigma}$ & RMS & $\rho$ \\
\hline TG & 22.1 & 46.3 & 34.6 & 6.8 & & \\
NMBU18S & 22.7 & 42.1 & 33.7 & 6.2 & & \\
NMBU18S-TG & -17.3 & 13.9 & -0.9 & 8.1 & 8.0 & 22.7 \\
\hline
\end{tabular}

values of around $\sim 20 \mathrm{~cm}$, which agree relatively well with their respective formal errors, and shows that NMBU18S only provides useful information on the coastal margin and toward the open ocean.

\section{Discussion and summary}

We have determined a coastal MSS surface for Norway solely based on new-generation altimetry, using the DIVA tool. DIVA gives analyses and consistent error fields similar to classical OI techniques, but with reduced computational demands, and taking the coastline into account. The NMBU18 coastal MDT contours are more realistic than previous attempts of deter- 
mining the coastal MDT, particularly evident in the formal error field.

In comparison with state-of-the-art global MSS models at the TGs, NMBU18 gives a $40 \%-60 \%$ improvement in terms of standard deviations of differences over DTU15/18 beta and CNES-CLS15, respectively. Along the three profiles all MSS fields largely agree, with standard deviations of differences ranging from $1.6 \mathrm{~cm}$ along the Svinøy section, to $4.4 \mathrm{~cm}$ along the Northern coast profile.

In order to investigate whether an altimetry-based coastal MSS is applicable for common vertical reference frame studies, we estimated the higherresolution NMBU18S MSS for the Sunnmøre testbed. In comparison with two permanent and 21 temporary TGs in the area, NMBU18S shows standard deviations of differences of $8.1 \mathrm{~cm}$ and a correlation of $22.7 \%$, but appears to be dominated by errors for the largest part of the area covered by the temporary TGs.

NMBU18S has to be used with care this close to the coast. By contrast to NMBU18, we were able to estimate a significant bias of NMBU18S with respect to the TGs in the testbed $(-21 \mathrm{~cm})$, although both models are based on the same altimetry data. Still, it is likely that this bias is indeed related to the altimetry data rather than, e.g., an offset in the vertical reference of the temporary TGs. When comparing Fig. 1b with Fig. 4a it becomes clear that most of the temporary TGs in the Sunnmøre testbed are in fact on the border of or inside an area which is largely void of altimetry observations. In this area, the NMBU18S values quickly approach zero, due to its relatively high resolution and small correlation length, and we obtain a negative bias. The errors grow accordingly large (Fig. 1d), and are on the level of the empirical error determined from the comparison with the two permanent and 21 temporary TGs. Still, NMBU18S performs roughly on the level of NMBU18 (standard deviations of differences of $\sim 8 \mathrm{~cm}$, but with notably lower correlation). As altimetry fills a data void in the coastal strip off the coast proper, and temporary TGs and ellipsoidal sea level observations from vessels equipped with GNSS receivers can represent sea level well inside the skerry landscape and fjords, it would be profitable to combine the data sets to obtain a best-approximation of the MSS field in the area. In such a combination, the NMBU18S error field should be used for correct weighting of the observations, and for calculating the error budget of the resulting combined MSS.

When looking at Table 3, as well as Figs. 5 and 6a, we observe that NMBU18 is relatively smooth compared to the validation data. Although 
this can be acceptable and in accordance with the available data points, it could also be a symptom of suboptimally determined analysis parameters, as both a too large $L$ as well as a too small SNR could cause over-smoothing. In principle, the divafit routine for determining $L$ and SNR performs similarly to the classical LSP approach, where an empirical covariance function is determined by computing the mean of product-sums of observations and the spherical distance between them, and an analytical model covariance function is adapted to it. The success of this approach is generally dependent on the number of available data points as well as their spatial resolution. However, differences between divafit and the classical approach can arise due to subtleties in the numerical implementation of the former (Jean-Marie Beckers, personal communication, 2018). First, the definition of $L$ in divafit is slightly different from the classical definition. In the classical definition the correlation length is the distance at which the covariance function $C$ reaches $0.5 \cdot C_{0}$, where $C_{0}=C(d=0)$ and $d$ is the distance. In divafit, $L$ is the distance which makes the kernel function of the DIVA functional closest to the empirical covariances. Second, divafit does not use function values for distances equal and close to zero, and filters the empirical covariances (giving a lower $C_{0}$ than in the classical definition). Third, spherical coordinates are not yet rigorously implemented in divafit, which could lead to inaccuracies in large-scale applications. These differences typically result in $L$ being larger and $C_{0}$ being smaller than in the classical covariance analysis. However, the field approximations might in the end be similar as a smaller $C_{0}$ gives a smaller SNR, which in turn compensates the larger value of $L$. In any case, the analysis parameters should be carefully tuned, and further investigations into their interaction are necessary.

Although our data editing scheme shows promising results, it is still difficult to flag and remove remaining outliers that can dominate the most sparsely observed areas. These outliers might result from an erroneous altimetry observation, but might also be due to an error in the coastal MSS, as the data editing is done on sea-level anomalies (SLAs), i.e., SSH values reduced by an MSS value. Alternatively, if the marine geoid is of sufficient quality, the data editing could be done on MDT values, but also in this case outliers are expected. Thus, investigation into a more elaborate data editing scheme close to the coast is meaningful, as well as an improved marine geoid.

Currently available geoid models in the area are accurate to a few centimeters. However, as they are tuned to fit validation data, the bulk of which is on land, they perform worse in the coastal zone and on the open 
ocean. In addition, they typically do not include the gravitational effect of the bathymetry, which is considerable along the Norwegian coast, with fjord depths reaching $\sim 1.3 \mathrm{~km}$.

Between 2012 and 2017, the NMA acquired about 3,800 additional gravity observations on land and sea in the Sunnmøre testbed (increasing the point density from $\sim 6 \mathrm{~km}$ to $\sim 2 \mathrm{~km}$ ), to prepare for a 1-cm geoid covering both land and ocean areas. There is ongoing work on determining a geoid model for the Sunnmøre testbed which will include the new gravity data as well as the effect of bathymetry. This model is expected to allow for an improved altimetry data editing, and in turn improved MDT estimate, transformation between vertical datums on land and on sea, as well as benefit sea-level and studies of coastal dynamics.

We regard NMBU18 and NMBU18S as promising initial validations of our method, and NMBU18S as a first attempt to provide altimetry observations that can be used for establishing a common vertical reference frame on land and at sea. When different ellipsoidal sea-level data are combined to provide a best-estimate of the coastal mean sea level surface, a reliable error description of each data type is needed. The proposed method for determining the coastal sea level from altimet y seems appropriate for such a combination.

\section{Acknowledgments}

Map data copyrighted OpenStreetMap contributors and available from https://www.openstreetmap.org. This study is part of the Norwegian University of Life Science's GOCODYN project, supported by the Norwegian Research Council under project number 231017. It is also part of the Norwegian Space Centre contract number NIT.01.18.15, 'Quality assurance and integration of Sentinel-1 and Sentinel-3 data'. Finally, we extend our thank to two anonymous reviewers for their useful comments and suggestions which improved the manuscript.

\section{References}

Agren, J., Strykowski, G., Bilker-Koivula, M., Omang, O., Märdla, S., Forsberg, R., Ellmann, A., Oja, T., Liepins, I., Parseliunas, E., Kaminskis, J., Sjöberg, L. and Valsson, G. (2016), 'On the development of the new Nordic gravimetric geoid model NKG2015', Paper presented at the 1st 
Joint Commission 2 and IGFS International Symposium on Gravity, Geoid and Height Systems, 19-23 Sep. 2016, Thessaloniki, Greece.

Albers, B. (2016), Towards a standardized European vertical datum for coastal mapping, in '2016 EUREF Symposium in San Sebastian, Spain, May 25-27, 2016'. www.euref.eu/symposia/2016SanSebastian/ 01-05-Alberts.pdf.

Andersen, O. B. (2013), Marine gravity and geoid from satellite altimetry, in F. Sansò and M. G. Sideris, eds, 'Geoid Determination: Theory and Methods', Springer Berlin Heidelberg, Berlin, Heidelberg, pp. 401-451. doi:10.1007/978-3-540-74700-0_9.

Andersen, O. B., Knudsen, P. and Stenseng, L. (2015), The DTU13 MSS (Mean Sea Surface) and MDT (Mean Dynamic Topography) from 20 Years of Satellite Altimetry, in S. Jin and R. Barzaghi, eds, 'International Association of Geodesy Symposia 144', Springer International Publishing, Cham, pp. 111-121. doi:10.1007/1345_2015_182.

Andersen, O. B., Nielsen, K., Knudsen, P., Hughes, C. W., Bingham, R., Fenoglio-Marc, L., Gravelle, M., Kern, M. and Polo, S. P. (2018), 'Improving the Coastal Mean Dynamic Topography by Geodetic Combination of Tide Gauge and Satellite Altimetry', Mar. Geod. 41(6), 517-545. doi:10.1080/01490419.2018.1530320.

Andersen, O. B. and Scharroo, R. (2011), Range and Geophysical Corrections in Coastal Regions: And Implications for Mean Sea Surface Determination, in S. Vignudelli, A. G. Kostianoy, P. Cipollini and J. Benveniste, eds, 'Coastal Altimetry', Springer Berlin Heidelberg, Berlin, Heidelberg, pp. 103-146. doi:10.1007/978-3-642-12796-0_5.

Beckers, J.-M., Barth, A., Troupin, C. and Alvera-Azcárate, A. (2014), 'Approximate and Efficient Methods to Assess Error Fields in Spatial Gridding with Data Interpolating Variational Analysis (DIVA)', J. Atm. Ocean. Tech. 31(2), 515-530. doi:10.1175/JTECH-D-13-00130.1.

Benveniste, J., Ambrózio, A., Restano, M. and Dinardo, S. (2016), 'SAR Processing on Demand Service for CryoSat-2 and Sentinel-3 at ESA GPOD', Geophysical Research Abstracts EGU2016-13084(18). 
Bonnefond, P., Verron, J., Aublanc, J., Babu, K. N., Bergé-Nguyen, M., Cancet, M., Chaudhary, A., Crétaux, J.-F., Frappart, F., Haines, B. J., Laurain, O., Ollivier, A., Poisson, J.-C., Prandi, P., Sharma, R., Thibaut, P. and Watson, C. (2018), 'The Benefits of the Ka-Band as Evidenced from the SARAL/AltiKa Altimetric Mission: Quality Assessment and Unique Characteristics of AltiKa Data', Remote Sensing 10(1). Article number 83, doi:10.3390/rs10010083.

Bosch, W., Dettmering, D. and Schwatke, C. (2014), 'Multi-mission crosscalibration of satellite altimeters: Constructing a long-term data record for global and regional sea level change studies', Remote sens. 6(3), 2255-2281. doi:10.3390/rs6032255.

Breili, K., Simpson, M. J. R. and Nilsen, J. E. Ø. (2017), 'Observed SeaLevel Changes along the Norwegian Coast', J. Mar. Sci. Eng. 5(3). Article number 29, doi:10.3390/jmse5030029.

Bronner, E., Guillot, A., Picot, N. and Noubel, J. (2013), 'SARAL/AltiKa Products Handbook'. SALP-MU-M-OP-15984-CN Issue: 2 rev 4 dated Dec. 9, 2013, 86p.

Dibarboure, G., Boy, F., Desjonqueres, J. D., Labroue, S., Lasne, Y., Picot, N., Poisson, J. C. and Thibaut, P. (2014), 'Investigating Short-Wavelength Correlated Errors on Low-Resolution Mode Altimetry', Journal of Atmospheric and Oceanic Technology 31(6), 1337-1362.

Drinkwater, M. R., Floberghagen, R., Haagmans, R., Muzi, D. and Popescu, A. (2003), GOCE: ESA's first Earth Explorer Core mission, in G. Beutler, M. R. Drinkwater, R. Rummel and R. Von Steiger, eds, 'Earth Gravity Field from Space - From Sensors to Earth Sciences, Space Sciences Series of ISSI', Springer Netherlands, Dordrecht, pp. 419-432. doi:10.1007/97894-017-1333-7_36.

Ekman, M. (1989), 'Impacts of geodynamic phenomena on systems for height and gravity', Bull. Géod. 63, 281-296. doi:10.1007/BF02520477.

ESA Sentinel-3 Team (2013), 'Sentinel-3 Product Handbook - September 2013'. 150p. 
Huang, J. (2017), 'Determining Coastal Mean Dynamic Topography by Geodetic Methods', Geophys. Res. Lett 44, 11,125-11,128. doi:10.1002/2017GL076020.

Idžanović, M., Ophaug, V. and Andersen, O. B. (2017), 'The coastal mean dynamic topography in Norway observed by CryoSat-2 and GOCE', Geophys. Res. Lett 44, 5609-5617. doi:10.1002/2017GL073777.

Koch, K.-R. (1999), Parameter Estimation and Hypothesis Testing in Linear Models, Springer-Verlag, Berlin, Heidelberg.

Mills, J. and Dodd, D. (2014), Ellipsoidally Referenced Surveying for Hydrography, FIG Publication No. 62, ISBN:978-87-92853-16-5, International Federation of Surveyors (FIG), Copenhagen, Denmark.

Moritz, H. (1980), Advanced Physical Geodesy, Herbert Wichmann, Karlsruhe, Germany. ISBN:3-87907-106-3.

OpenStreetMap contributors (2018), 'Planet dump retrieved from https://planet.osm.org ', https://www openstreetmap.org.

Ophaug, V., Breili, K. and Gerlach, C. (2015), 'A comparative assessment of coastal mean dynamic topography in Norway by geodetic and ocean approaches', Journal of Geophysical Research: Oceans 120, 7807-7826.

Petit, G. and Luzum, B., eds (2010), IERS Conventions, Verlag des Bundesamts für Kartographie und Geodäsie, Frankfurt am Main, Germany. IERS Technical Note no. 36.

Pineau-Guillou, L. and Dorst, L. (2013), Creation of Vertical Reference Surfaces at Sea Using Altimetry and GPS, in Z. Altamimi and X. Collilieux, eds, 'Reference Frames for Applications in Geosciences, International Association of Geodesy Symposia 138', Springer-Verlag Berlin Heidelberg, pp. 229-235. doi:10.1007/978-3-642-32998-2_33.

Pujol, M.-I., Schaeffer, P., Faugre, Y., Raynal, M., Dibarboure, G. and Picot, N. (2018), 'Gauging the Improvement of Recent Mean Sea Surface Models: A New Approach for Identifying and Quantifying Their Errors', Journal of Geophysical Research: Oceans 123(8), 5889-5911. 
Raney, R. K. (1998), 'The delay/Doppler radar altimeter', IEEE Transactions on Geoscience and Remote Sensing 36(5), 1578-1588.

Raynal, M., Labroue, S., Moreau, T., Boy, F. and Picot, N. (2018), 'From conventional to Delay Doppler altimetry: A demonstration of continuity and improvements with the CryoSat-2 mission', Adv. Space Res. 62(6), 1564-1575. doi:10.1016/j.asr.2018.01.006.

Simpson, M. J. R., Ravndal, O. R., Sande, H., Nilsen, J. E. Ø., Kierulf, H. P., Vestøl, O. and Steffen, H. (2017), 'Projected 21st Century Sea-Level Changes, Observed Sea Level Extremes, and Sea Level Allowances for Norway', J. Mar. Sci. Eng. 5(3). Article number 36, doi: $10.3390 /$ jmse 5030036 .

Slobbe, D. C., Klees, R., Verlaan, M., Dorst, L. L. and Gerritsen, H. (2013), 'Lowest Astronomical Tide in the North Sea Derived from a Vertically Referenced Shallow Water Model, and an Assessment of its Suggested Sense of Safety', Mar. Geod. 36, 31-71. doi:10.1080/01490419.2012.743493.

Solheim, D. (2000), New height reference surfaces for Norway, in J. A. Torres and H. Hornik, eds, 'Report on the Symposium of the IAG Subcommission for Europe (EUREF) in Troms $\varnothing, 22-24$ Jun.', Verlag der Bayerischen Akademie der Wissenschaften, München, pp. 154-158.

Stammer, D. and Cazenave, A., eds (2017), Satellite Altimetry over Oceans and Land Surfaces, CRC Press, Boca Raton, USA. ISBN:978-1-4987-43457 .

Torge, W. and Müller, J. (2012), Geodesy, 4th ed., de Gruyter, Berlin, Germany. ISBN:978-3-11-025000-8.

Troupin, C., Barth, A., Sirjacobs, D., Ouberdous, M., Brankart, J.-M., Brasseur, P., Rixen, M., Alvera-Azcárate, A., Belounis, M., Capet, A., Lenartz, F., Toussaint, M.-E. and Beckers, J.-M. (2012), 'Generation of analysis and consistent error fields using the Data Interpolation Variational Analysis (DIVA)', Ocean Model. 52-53, 90-101.

Verron, J., Sengenes, P., Lambin, J., Noubel, J., Steunou, N., Guillot, A., Picot, N., Coutin-Faye, S., Sharma, R., Gairola, R. M., Raghava Murthy, D. V. A., Richman, J. G., Griffin, D., Pascual, A., Rémy, F. and Gupta, 
P. K. (2015), 'The SARAL/AltiKa Altimetry Satellite Mission', Mar. Geod. 38, 2-21. doi:10.1080/01490419.2014.1000471.

Vignudelli, S., Kostianoy, A. G., Cipollini, P. and Benveniste, J., eds (2011), Coastal Altimetry, Springer, Berlin Heidelberg. doi:10.1007/978-3-64212796-0.

Villadsen, H., Deng, X., Andersen, O. B., Stenseng, L., Nielsen, K. and Knudsen, P. (2016), 'Improved inland water levels from SAR altimetry using novel empirical and physical retrackers', J. Hydrol. 537, 234-247. doi:10.1016/j.jhydrol.2016.03.051.

Wingham, D. J., Francis, C. R., Baker, S., Bouzinac, C., Brockley, D.and Cullen, R., de Chateau-Thierry, P., Laxon, S. W., Mallow, U., Mavrocordatos, C., Phalippou, L., Ratier, G., Rey, L., Rostan, F., Viau, P. and Wallis, D. W. (2006), 'CryoSat: A mission to determine the fluctuations in Earth's land and marine ice fields', Adv. Space Res. 37, 841-871. doi:10.1016/j.asr.2005.07.027.

Woodworth, P. L., Hughes, C., Bingham, R. J. and Gruber, T. (2012), 'Towards worldwide height system unification using ocean information', $J$. Geod. Sci. 2, 302-318. doi: 10.2578/v10156-012-0004-8. 